\title{
Short-Term City Electric Load Forecasting with Considering Temperature Effects: An Improved ARIMAX Model
}

\author{
Herui Cui and Xu Peng \\ School of Economics and Management, North China Electric Power University, Baoding 071003, China \\ Correspondence should be addressed to Xu Peng; donaldpengxu@163.com
}

Received 13 April 2015; Revised 9 June 2015; Accepted 21 June 2015

Academic Editor: Marco Mussetta

Copyright (C) 2015 H. Cui and X. Peng. This is an open access article distributed under the Creative Commons Attribution License, which permits unrestricted use, distribution, and reproduction in any medium, provided the original work is properly cited.

\begin{abstract}
Short-term electric load is significantly affected by weather, especially the temperature effects in summer. External factors can result in mutation structures in load data. Under the influence of the external temperature factors, city electric load cannot be easily forecasted as usual. This research analyzes the relationship between electricity load and daily temperature in city. An improved ARIMAX model is proposed in this paper to deal with the mutation data structures. It is found that information amount of the improved ARIMAX model is smaller than that of the classic method and its relative error is less than AR, ARMA and SigmoidFunction ANN models. The forecasting results are more accurately fitted. This improved model is highly valuable when dealing with mutation data structure in the field of load forecasting. And it is also an effective technique in forecasting electric load with temperature effects.
\end{abstract}

\section{Introduction}

Short-term load forecasting (STLF) is mainly used to forecast the power load for the next few days or week [1-3]. It plays an important role in the modern electricity Demand Side Management (DSM), as its accuracy directly affects the economic cost of operators in the electricity market. Accurate load forecasting is helpful for security, stability, and economic operation in power grid. It is also advantageous in making reasonable arrangements for maintenance plan. Meanwhile, power load forecasting can optimize power system dispatch and reduce production cost.

Short-term daily peak power load in summer fluctuates regularly, showing an obvious periodical characteristic. It is greatly affected by temperature, wind, precipitation, and other meteorological factors. There are significant mutation structures in load data [4-6]. There are traditional methods in power load forecasting, such as regression model, gray model, support vector machines, neural networks, and time series. Ramón Cancelo et al. [7] used Red Eléctrica de España (REE) to forecast the electricity load from a day to a week ahead. Hipperta et al. [8] adapted large neural networks in electricity load forecasting to handle nonlinear time series data. Felipe Amarala and Castro Souza [9] used smooth transition periodic autoregressive (STPAR) models for short-term load forecasting. Amjady and Keynia [10] proposed a new neural network learning algorithm based on a new modified harmony search technique. This learning algorithm is widely used to search the solution space in various directions, by which overfitting problem and trapping in local minima and dead bands can be avoided. Wangdi et al. [11] adapted ARIMAX model to determine predictors of malaria for the subsequent month. And the test showed that prediction accuracy has been greatly improved. Chadsuthi et al. [12] studied seasonal leptospirosis transmission and the association with rainfall and temperature by using ARIMAX model showing that factoring in rainfall (with an 8-month lag) yields the best model for the northern region. The above forecasting methods are obviously effective in dealing with mutation structures and intelligent algorithms. However, they are not ideal in practical operation due to the limitation of data and laboratory equipment. The generalization capability is also weak. Traditional time series forecasting methods highlight the time role, without considering the external factor effects. Thus, the forecasting accuracy of time series methods is poor, with obvious defect $[13,14]$. Based on the above research, an improved ARIMAX model 
is proposed here by combining the traditional time series with regression analysis to forecast short-term electric load, which has a strong practice value in the short-term power load forecasting field. This model fills the gaps of external effects on electric load. The prediction result showed that the improved ARIMAX model has a smaller model information amount than $\operatorname{AR}(p)$ or $\operatorname{ARMA}(p, q)[15,16]$.

\section{Sigmoid-Function ANN Model}

ANN (Artificial Neural Network) is very practical forecasting technology in short-term electric load forecasting fields, especially for those nonlinear data. The basic concepts about ANN are shown as

$$
\text { Sigmoid function: } f\left(\operatorname{Net}_{k j}\right)=\frac{1}{1+e^{-\mathrm{Net}_{k j}}} \text {, }
$$

where Net $_{k j}$ is the state of network unit $u_{j}$. Consider

$$
\text { The output unit: } \begin{aligned}
o_{k j} & =\frac{1}{1+\exp \left(-\sum_{i} \omega_{j i} o_{k i}-\theta_{j}\right)} \\
& =\frac{1}{1+e^{- \text {Net }_{k j}}} .
\end{aligned}
$$

Through the operating of first-order derivative to output unit, $f^{\prime}\left(\mathrm{Net}_{k j}\right)$ is obtained as follows:

$$
f^{\prime}\left(\operatorname{Net}_{k j}\right)=\frac{\delta o_{k j}}{\delta \operatorname{Net}_{k j}}=o_{k j}\left(1-o_{k j}\right),
$$

Output layer unit: $\delta_{k j}=\left(t_{\partial j}-o_{k j}\right) o_{k j}\left(1-o_{k j}\right)$,

Hidden layer unit: $\delta_{k j}=o_{k j}\left(1-o_{k j}\right) \sum_{m} \delta_{k m} \omega_{m j}$,

Weight tuning function: $\Delta \omega_{j i}(t+1)=\eta \delta_{k j} o_{k j}$.

The specific algorithm of Sigmoid-Function ANN model is shown as follows:

(1) The initial value of weight or threshold is defined as $\omega_{j i}(0)$, while $\theta_{j}(0)$ is small random number.

(2) Training samples are input vector $X_{k},(k=1,2$, $\ldots, P)$; expectation output $d_{k},(k=1,2, \ldots, P)$. Steps from (3) to (5) are carried out for each input sample.

(3) Computing actual output and the state of hidden units in network

$$
o_{k j}=f_{j}\left(\sum_{i} \omega_{j i} o_{k i}+\theta_{j}\right) .
$$

(4) Calculation training error

$$
\begin{aligned}
& \text { Output layer: } \delta_{k j}=\left(t_{\partial j}-o_{k j}\right) o_{k j}\left(1-o_{k j}\right), \\
& \text { Hidden layer: } \delta_{k j}=o_{k j}\left(1-o_{k j}\right) \sum_{m} \delta_{k m} \omega_{m j} \text {. }
\end{aligned}
$$

(5) Correcting weights and thresholds

$$
\begin{aligned}
& \omega_{j i}(t+1)=\omega_{j i}(t)+\eta \delta_{j} o_{k i}+\alpha\left[\omega_{j i}(t)-\omega_{j i}(t-1)\right], \\
& \theta_{j i}(t+1)=\theta_{j}(t)+\eta \delta_{j}+\alpha\left[\theta_{j}(t)-\theta_{j}(t-1)\right] .
\end{aligned}
$$

(6) When index $k$ is located at $P$, judging if $E \leq \varepsilon$.

\section{Time Series Theory}

Time series is a typical time-domain analysis method. It can be used to reveal the internal laws of the sequences from the perspective of autocorrelation.

Typical time-domain analysis steps are the following:

(1) Observing sequence features.

(2) Selecting the appropriate fitted model according to the features computed by SAS.

(3) Model testing and optimization process.

(4) Using fitted model to infer the nature of sequence.

Core contents of time series analysis method are proposed by American statistician George E. P. Box and United Kingdom statistician Gwilym M. Jenkins in their book Time Series Analysis Forecasting and Control, in which it is called autoregressive moving average model (ARIMA). Some important concepts are displayed here.

Stationarity. $\left\{x_{t}\right\}$ is set as time series, and $m \in \ell^{*},\left(\ell^{*}\right.$ is positive integer) $t_{1}, t_{2}, \ldots, t_{m} \in T, \forall \tau \in \not{c}$, ( $\varnothing$ is integer), $\exists F_{t_{1}, t_{2}, \ldots, t_{m}}\left(x_{1}, x_{2}, \ldots, x_{m}\right)=F_{t_{1+\tau}, t_{2+\tau}, \ldots, t_{m+\tau}}\left(x_{1}, x_{2}, \ldots, x_{m}\right)$, named $\left\{x_{t}\right\}$ for strictly stationary time series.

White Noise. Time series $\left\{x_{t}\right\}$ meet the condition (1) $\forall t \in$ $T, \exists E X_{t}=\mu$ (2) $\forall t, s \in T$; then

$$
\gamma(t, s)= \begin{cases}\sigma^{2}, & t=s \\ 0, & t \neq s\end{cases}
$$

named $\left\{x_{t}\right\}$ for white noise sequence or displayed as

$$
X_{t} \sim \mathrm{WN}\left(\mu, \sigma^{2}\right)
$$

Definition 1. The model is named autoregressive moving average model, if it contains the following structures, abbreviated as $\operatorname{ARMA}(p, q)$ :

$$
\begin{aligned}
x_{t}= & \phi_{0+} \phi_{1} x_{t-1}+\cdots+\phi_{p} x_{t-p}+\varepsilon_{t}-\theta_{1} \varepsilon_{t-1}-\cdots \\
& -\theta_{q} \varepsilon_{t-q}, \quad \phi_{p} \neq 0, \theta_{q} \neq 0, \\
E\left(\varepsilon_{t}\right)= & 0, \\
\operatorname{Var}\left(\varepsilon_{t}\right)= & \sigma_{\varepsilon}^{2}, \\
E\left(\varepsilon_{t} \varepsilon_{s}\right)= & 0, \quad s \neq t, \\
E\left(x_{s} \varepsilon_{t}\right)= & 0, \quad \forall s<t .
\end{aligned}
$$


Introduced delay operator $B$, it can also be presented as

$$
\Phi(B) x_{t}=\Theta(B) \varepsilon_{t} .
$$

Cointegration Theory. The cointegration theory was put forward by Engle and Granger in 2001 [17]. Model can be calculated without the requirement that all sequences are stationary, if the cointegration relationship is obvious. The typical cointegration test is EG test [18-20].

Definition 2. Supposing that the response variable $\left\{y_{t}\right\}$ and the input variable sequences $\left\{x_{1}\right\}, \ldots,\left\{x_{k}\right\}$ are all stationary, the regression model is established in response to the input variable sequences and response sequences:

$$
\begin{aligned}
& y_{t}=\mu+\sum_{i=1}^{k} \frac{\Theta_{i}(B)}{\Phi_{i}(B)} B^{l_{i}} x_{i t}+\varepsilon_{t}, \\
& \varepsilon_{t}=\frac{\Theta(B)}{\Phi(B)} a_{t},
\end{aligned}
$$

abbreviated as ARIMAX model.

In the actual modeling process, an improved ARIMAX model is proposed to forecast the short-term electric load. The specific process is displayed below.

\section{The Improved ARIMAX Modeling Process}

\subsection{Modeling Steps. These are as follows}

(1) Perform logarithmic transformation on the original response sequence and the inputted sequences in order to meet the homogeneity of variance assumption.

(2) Checking the stationarity of logarithmic transformation sequences,

$$
\left\{\ln y_{t}\right\} ;\left\{\ln x_{1}\right\}, \ldots,\left\{\ln x_{k}\right\} .
$$

If the sequences are stationary, move on to the next step; if not, conduct differential operation to the logarithmic sequences and testing stationarity again; then execute the second-order differential operation until the stationarity is satisfied.

(3) Establishing the ARMA model about $\left\{\nabla^{n} \ln x_{t}\right\}$,

$$
\nabla^{n} \ln x_{i t}=\frac{\Theta_{x i}(B)}{\Phi_{x i}(B)} \varepsilon_{x i t} .
$$

$\left\{\nabla^{n} \ln x_{t}\right\}$ are N-order difference stationary inputted sequences.

(4) Establishing the ARMA model about $\left\{\nabla^{n} \ln y_{t}\right\}$,

$$
\nabla^{n} \ln y_{i t}=\frac{\Theta_{y i}(B)}{\Phi_{y i}(B)} \varepsilon_{y i t} .
$$

$\left\{\nabla^{n} \ln y_{t}\right\}$ are the $\mathrm{N}$-order difference stationary response sequences.
(5) Exploring the correlation coefficient between the stationary $\mathrm{N}$-order difference logarithmic sequences " $\nabla^{n} \ln y_{t}$ " and " $\nabla^{n} \ln x_{t}$ " to determine the structure of improved ARIMAX model. This step is the improved part for traditional ARIMAX model. Therefore, the revised ARIMAX model can be calculated as follows:

$$
y_{t}^{*}=\mu+\sum_{i=1}^{k} \frac{\Theta_{i}(B)}{\Phi_{i}(B)} B^{l_{i}} x_{i t}^{*}+\varepsilon_{t} .
$$

(6) Fitting residual sequence $\left\{\varepsilon_{t}\right\}$

$$
\varepsilon_{t}=\frac{\Theta(B)}{\Phi(B)} a_{t} .
$$

$\left\{a_{t}\right\}$ is a zero mean white noise sequence.

Based on the above steps the improved ARIMAX model can be applied into load forecasting process.

\subsection{Modeling Flowchart. See Figure 1.}

\section{Load Forecasting with ARMA Model}

5.1. Load Data. The table in the appendix shows the daily maximum power load data and the maximum temperatures in a city from 1st June to 14th August (see Table 12). In this paper, the data is used to explore the classical time series models and ANN models are used to firstly forecast load. In Section 6, an improved ARIMAX model is established to compare the prediction accuracy [21-23].

It can be seen in Figure 2 that load data has an upward trend and clear cyclical fluctuations by observing the sequences, showing that the sequences are nonstationary $[24,25]$.

5.2. Establishing ARMA Model. After the time series analysis on the load data by SAS software, autocorrelation table is previously mentioned. Table 1 shows that the autocorrelation coefficients of the sequences are always positive [26-28]. It can be inferred that daily peak power load data is nonstationary series with a monotonic trend, which is shown in Figure 2.

At the same time, the partial autocorrelation table can be obtained. Table 2 shows that only the first-order partial autocorrelation coefficient is significantly greater than twotime standard errors [29]. The rest partial autocorrelation coefficients rapidly decline to zero, making random fluctuations within two-time standard deviation ranges. Thus it can be regarded as the first-order truncation.

According to white noise test, statistic $P$ (probability) is less than 0.05; thus the sequence is nonwhite noise. Then, the $\mathrm{AR}(1)$ model is applied to forecast power load data. In residual autocorrelation coefficient test about AR(1) model, it is shown that statistic $P$ is larger than 0.05 ; thus this model applies.

After the SAS processing, AR(1) model can be presented as

$$
x_{t}=2895.82+\frac{\varepsilon_{t}}{1-0.90534 * B} .
$$



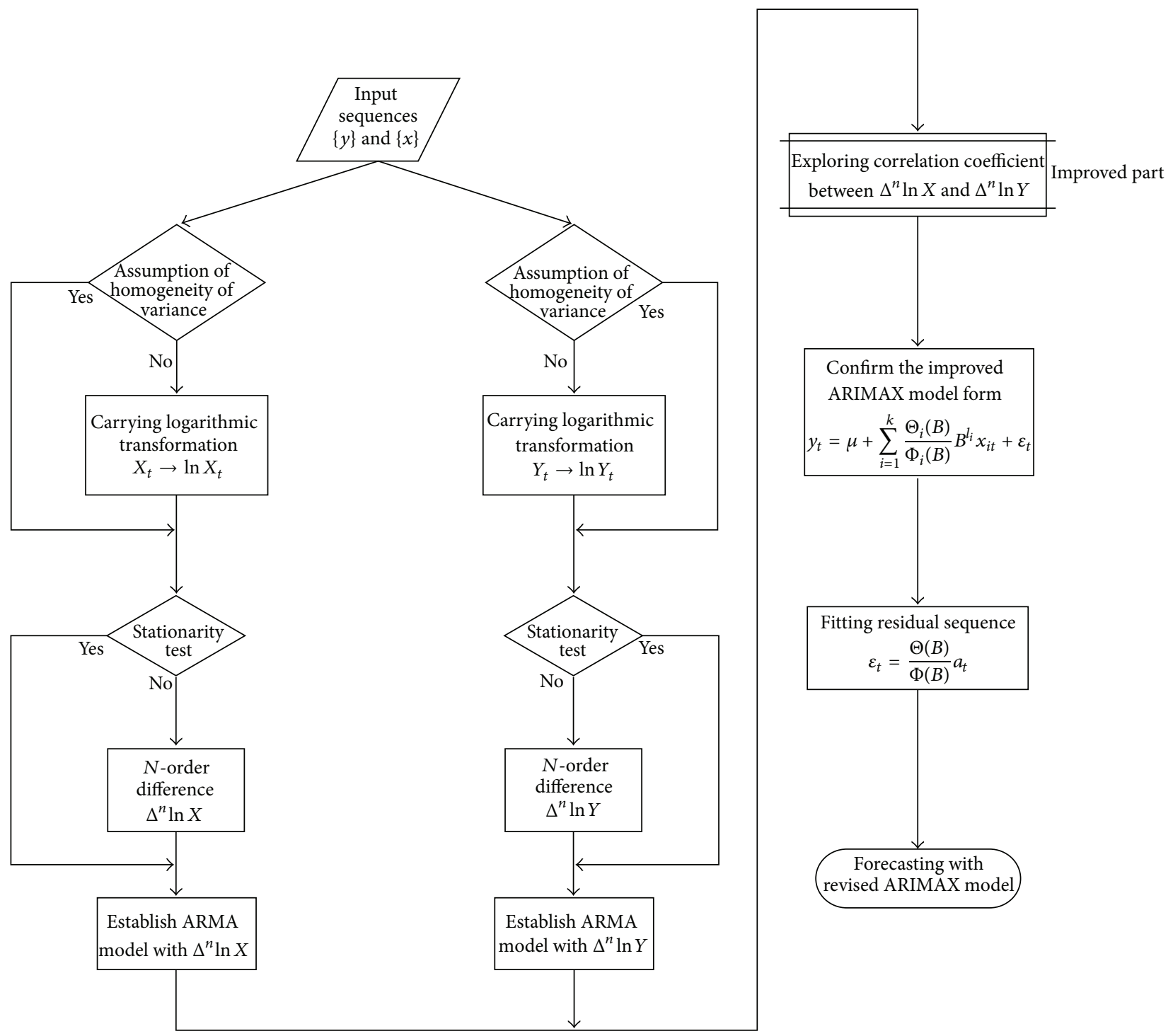

FIgURE 1: ARIMAX modeling flowchart.

TABle 1: Autocorrelation table.

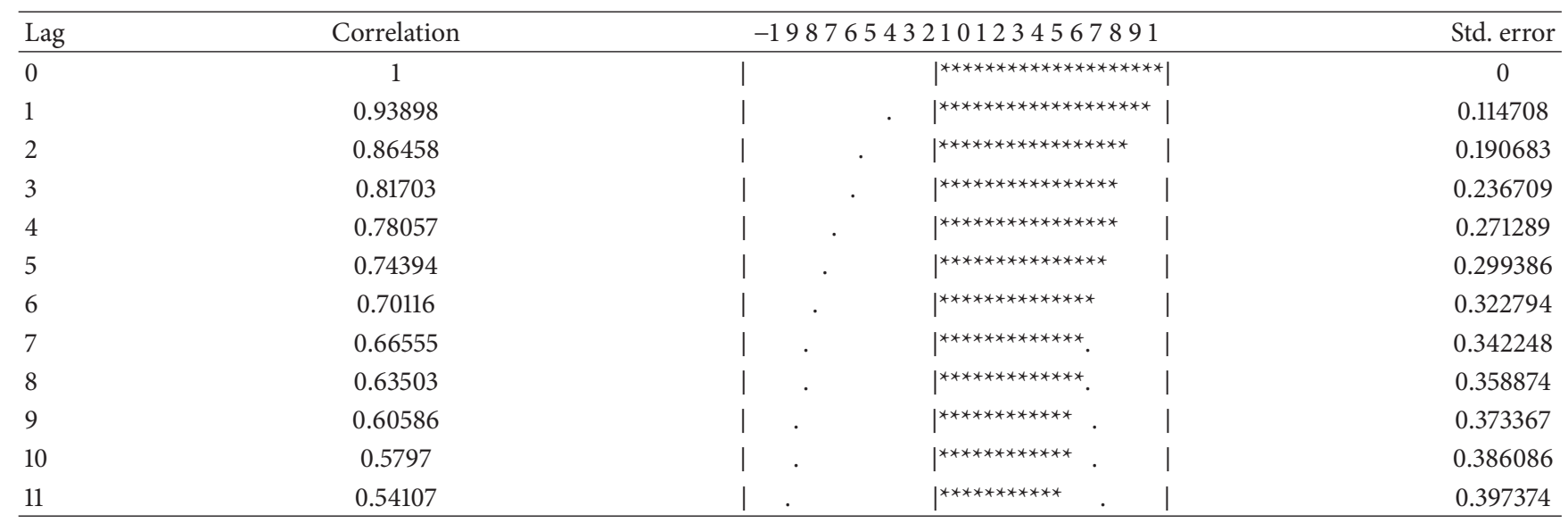




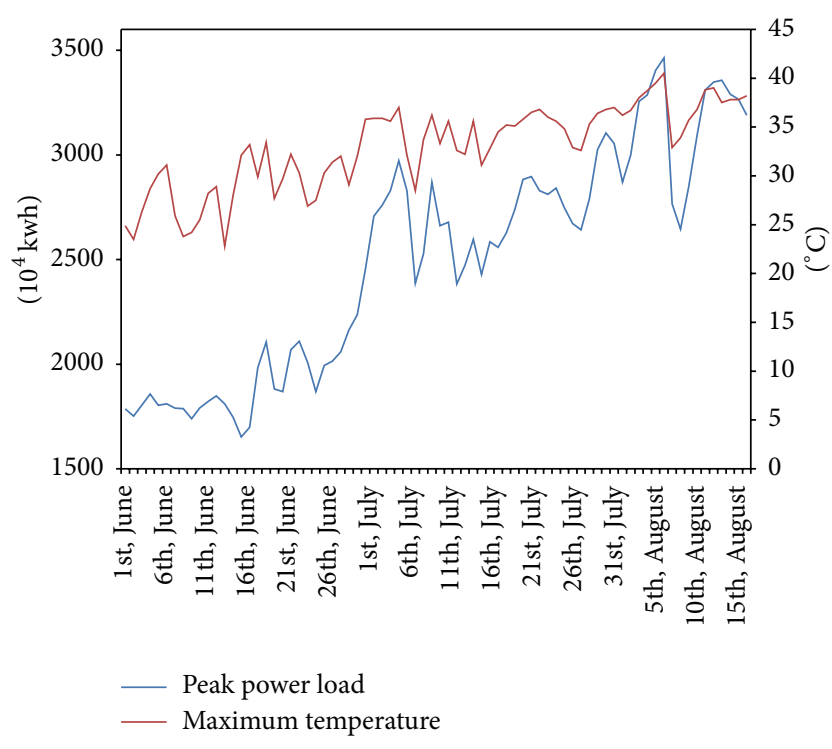

FIGURE 2: Load and temperature figure.

TABLE 2: Partial autocorrelation table.

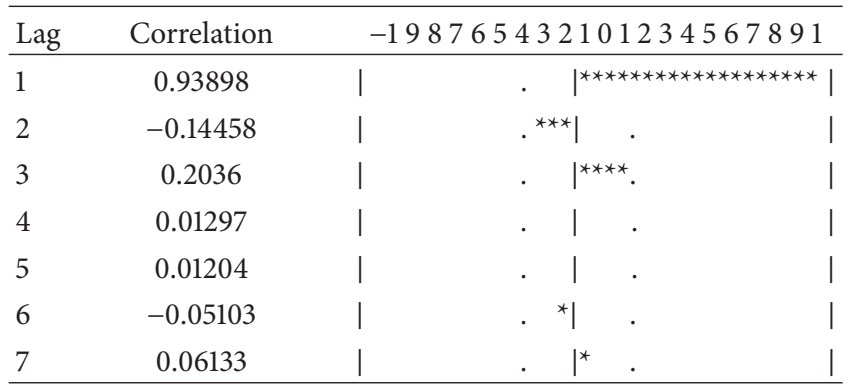

In order to optimize the ARMA model, the minic option is used to detect the best order [30]. Setting $\operatorname{ARMA}(p, q)$ model as $x_{t}=\mu+(\Theta(B) / \Phi(B)) \varepsilon_{t}$, the option detects the $\operatorname{ARMA}(3,2)$. The $\operatorname{ARMA}(p, q)$ model is presented as

$$
\begin{aligned}
x_{t}= & 2949.334 \\
& +\frac{1-0.97485 B+0.3208 B^{2}}{1-1.97331 B+1.49699 B^{2}-0.52368 B^{3}} \varepsilon_{t} .
\end{aligned}
$$

\section{Load Forecasting with Improved ARIMAX Model}

6.1. Testing Statistics. Regardless of the kinds of models, the $P$ value of test statistic $\tau$ is significantly greater than 0.05 by $\mathrm{ADF}$ test. Daily maximum power load data series are markedly nonstationary. Therefore, the following analysis is conducted on nonstationary data sequence.

Firstly, performing logarithmic transformation on the original sequence,

$$
x, y \rightarrow \ln x, \ln y
$$

TABLE 3: Autocorrelation check for white noise.

\begin{tabular}{lc}
\hline To lag & Pr $>$ ChiSq \\
\hline 12 & 0.1066 \\
18 & 0.2526 \\
\hline
\end{tabular}

TABLE 4: Augmented Dickey-Fuller unit root tests.

\begin{tabular}{lcccc}
\hline Type & Lags & $\operatorname{Pr}<$ Rho & $\operatorname{Pr}<$ Tau & $\operatorname{Pr}>F$ \\
\hline \multirow{3}{*}{ Zero means } & 0 & $<0.0001$ & $<0.0001$ & \\
& 1 & 0.0001 & $<0.0001$ & \\
\hline \multirow{3}{*}{ Single mean } & 2 & 0.0001 & $<0.0001$ & \\
& 0 & 0.0007 & 0.0001 & 0.001 \\
& 1 & 0.0001 & 0.0001 & 0.001 \\
& 2 & 0.0002 & 0.0001 & 0.001 \\
\hline
\end{tabular}

Thus the sequences can meet the homogeneity of variance. The white noise test of $\ln x$ sequence indicates that the $\ln x$ sequence is a nonwhite noise sequence. Unit root test shows that the $P$ value of $\tau$ statistic is significantly greater than 0.05. It is suggested that $\ln x$ sequence is nonstationary. There is one unit root in $\ln x$ sequence at least. And the analysis on $\ln y$ sequence is similar to that of $\ln x$ [23-25].

Secondly, operating first-order differential operators to $\left\{\ln y_{t}\right\}$ and $\left\{\ln x_{t}\right\}$ sequences to get stationary $\left\{\Delta \ln y_{t}\right\}$ and $\left\{\Delta \ln x_{t}\right\}$,

$$
\ln x_{t}, \ln y_{t} \longrightarrow \Delta \ln x_{t}, \Delta \ln y_{t} .
$$

Thirdly, operate stationary test and white noise test to logarithmic sequence after first-order differential $\left\{\Delta \ln y_{t}\right\}$ and $\left\{\Delta \ln x_{t}\right\}$. The test result shows that the $P$ value of white noise test is greater than 0.05 , which means that $\left\{\Delta \ln y_{t}\right\}$ and $\left\{\Delta \ln x_{t}\right\}$ sequences are pure random white noise sequences [26]. And the $P$ value of $\tau$ statistic is less than 0.05 , showing that $\left\{\Delta \ln y_{t}\right\}$ and $\left\{\Delta \ln x_{t}\right\}$ sequences are stationary series. Until now, the test analysis has been finished.

6.2. Computing $\Delta \ln y_{t}$ and $\Delta \ln x_{t}$ Sequences Model. Firstly, the $\Delta \ln y$ model is established. The test shows that $\Delta \ln y$ is a stationary white noise sequence; thus the fitting model is

$$
\Delta \ln y=\varepsilon_{t} .
$$

Secondly, the $\Delta \ln x$ model is established (see Table 6). The test results obtained by SAS from Tables 3 to 5 show that $\Delta \ln x$ is a stationary white noise sequence (the $P$ value in Table 3 is larger than 0.05 , while the $P$ value in Table 4 is smaller than 0.05). The best order for $\operatorname{ARMA}(p, q)$ model is $[\operatorname{AR}(0), \operatorname{MA}(4)]$. Therefore, the fitting model is $\operatorname{ARMA}(0,4)$ or MA(4) model. The constant term is not significant, using the noint option to remove the intercept. The final fitting model is shown as [31]

$$
\Delta \ln x_{t}=\left(1-0.45098 B^{4}\right) \varepsilon_{t} .
$$


TABLE 5: Minimum information criterion.

\begin{tabular}{lcccccc}
\hline Lags & $\mathrm{MA}(0)$ & $\mathrm{MA}(1)$ & $\mathrm{MA}(2)$ & $\mathrm{MA}(3)$ & $\mathrm{MA}(4)$ & $-\mathrm{MA}(5)$ \\
\hline $\mathrm{AR}(0)$ & -5.14349 & -5.22355 & -5.48448 & -5.51557 & -5.51716 & -5.51704 \\
$\mathrm{AR}(1)$ & -5.13228 & -5.19252 & -5.42776 & -5.4607 & -5.4677 & -5.48567 \\
$\mathrm{AR}(2)$ & -5.35327 & -5.40243 & -5.37285 & -5.41553 & -5.41986 & -5.46426 \\
$\mathrm{AR}(3)$ & -5.3958 & -5.42964 & -5.39755 & -5.36473 & -5.3641 & -5.41041 \\
$\mathrm{AR}(4)$ & -5.40213 & -5.42436 & -5.39489 & -5.36661 & -5.30905 & -5.37159 \\
$\mathrm{AR}(5)$ & -5.4457 & -5.422 & -5.40418 & -5.3893 & -5.33506 & -5.32363 \\
\hline
\end{tabular}

Minimum table value: $\operatorname{BIC}(0,4)=-5.51716$

TABLE 6: Fitting parameter of $\Delta \ln x$ model.

\begin{tabular}{lccccc}
\hline Parameter & Estimate & Standard error & $t$-value & Approx. Pr $>|t|$ & $<0.0001$ \\
\hline MA $(1,1)$ & 0.45098 & 0.10373 & 4.35 & 1 \\
\hline
\end{tabular}

TABLE 7: Relationship number table of $\Delta \ln y$ and $\Delta \ln x$.

\begin{tabular}{|c|c|c|c|c|c|}
\hline Lag & Correlation & \multicolumn{4}{|c|}{-198765432101234567891} \\
\hline-3 & 0.05145 & | & . $\left.\right|^{*}$ & & | \\
\hline-2 & -0.24894 & | & $* * * * * 1$ & . & । \\
\hline-1 & -0.17628 & I & $\cdot * * * * 1$ & . & | \\
\hline 0 & 0.49787 & I & . $\quad 1^{* x}$ & $* * * * * * * * *$ & I \\
\hline 1 & 0.15016 & | & $1^{* x}$ & $* *$ & । \\
\hline 2 & -0.02468 & | & . 1 & & । \\
\hline 3 & -0.05311 & । & . $\quad * 1$ & . & । \\
\hline
\end{tabular}

TABLE 8: Parameter estimates of REG procedure.

\begin{tabular}{lcccrr}
\hline Variable & Dependent variable & Parameter estimates & Standard error & $t$-value & Pr $>|t|$ \\
\hline$\Delta \ln x$ & $\Delta \ln y$ & 0.37098 & 0.07442 & 4.98 & $<0.0001$ \\
\hline
\end{tabular}

TABLE 9: Autocorrelation check of residuals.

\begin{tabular}{lc}
\hline To lag & Pr $>$ ChiSq \\
\hline 6 & 0.0578 \\
12 & 0.0687 \\
18 & 0.1588 \\
\hline
\end{tabular}

TABLE 10: Crosscorrelation check of residuals with input $\ln x$.

\begin{tabular}{lc}
\hline To lag & Pr $>$ ChiSq \\
\hline 5 & 0.0581 \\
11 & 0.0634 \\
17 & 0.0732 \\
\hline
\end{tabular}

6.3. Computing Load Data with Improved ARIMAX Model. The above model is used to filter input variable sequence $\left\{\Delta \ln x_{1}\right\} \cdots\left\{\Delta \ln x_{k}\right\}$ and the response variable sequence $\left\{\Delta \ln y_{t}\right\}$. The mutual relationships numbers between the independent variables and the response variable are calculated after filtration by ARIMA analysis process.

It can be found in Table 7 that only the 0 -order delay mutual relationship number is significantly nonzero, which means that there is no hysteretic effect between response sequence and input sequences. Therefore, the model should be treated in the same period.

The regression analysis in Table 8 shows that the final regression coefficient is 0.37098 .

The statistics test is carried out on residual sequence, showing that the residual sequence is stationary white noise sequence $(\operatorname{Pr}>0.05)$. The fitted model for residual sequence is $\varepsilon_{t}=a_{t}$, and $a_{t}$ is zero mean white noise sequence [32-35].

It is known that there is significant correlation in the zero-order between the two sequences in Table 7. The same period model is established between $\Delta \ln y$ and $\Delta \ln x$, based on the parameter estimates in Table 8 and tests in Tables 9 10. The $P$ value in Table 9 is larger than 0.05 ; thus the autocorrelation check of residuals shows that the model is effective for forecasting loads:

$$
\begin{aligned}
\Delta \ln y_{t} & =0.37098 \Delta \ln x_{t}+\varepsilon_{t}, \\
\varepsilon_{t} & =a_{t} .
\end{aligned}
$$

The load from 15th to 31st is forecasted according to the improved ARIMAX model. 
TABLE 11: Predictions of different models.

\begin{tabular}{|c|c|c|c|c|c|}
\hline Obs. & $\begin{array}{l}\text { Actual power load } \\
\text { data }\end{array}$ & $\begin{array}{l}\text { Prediction value of } \\
\text { improved ARIMAX }\end{array}$ & $\begin{array}{l}\text { Prediction value of } \\
\text { AR(1) }\end{array}$ & $\begin{array}{l}\text { Prediction value of } \\
\operatorname{ARMA}(3,2)\end{array}$ & $\begin{array}{c}\text { Prediction value of } \\
\text { Sigmoid-Function } \\
\text { ANN }\end{array}$ \\
\hline 16 & 2685 & 2678 & 2648 & 2699 & 2698 \\
\hline 17 & 2833 & 2820 & 2810 & 2855 & 2844 \\
\hline 18 & 2924 & 2930 & 2917 & 2934 & 2934 \\
\hline 19 & 3112 & 3122 & 3128 & 3130 & 3128 \\
\hline 20 & 2393 & 2400 & 2428 & 2441 & 2412 \\
\hline 21 & 2570 & 2600 & 2650 & 2661 & 2598 \\
\hline 22 & 2689 & 2709 & 2723 & 2741 & 2699 \\
\hline 23 & 2730 & 2788 & 2796 & 2801 & 2812 \\
\hline 24 & 2597 & 2638 & 2654 & 2687 & 2611 \\
\hline 25 & 2216 & 2219 & 2225 & 2258 & 2215 \\
\hline 26 & 1935 & 1929 & 1971 & 1995 & 1952 \\
\hline 27 & 1826 & 1822 & 1910 & 1984 & 1857 \\
\hline 28 & 1897 & 1850 & 1927 & 1968 & 1904 \\
\hline 29 & 1945 & 1926 & 2018 & 2100 & 1965 \\
\hline 30 & 2244 & 2230 & 2101 & 2154 & 2264 \\
\hline 31 & 2261 & 2258 & 2177 & 2137 & 2274 \\
\hline & AIC Criterion & -72.7 & 381.4 & 433.8 & 78.6 \\
\hline & SBC Criterion & -71.5 & 383.9 & 436.6 & 79.2 \\
\hline & MAE & 0.0037 & 0.0389 & 0.0494 & 0.0185 \\
\hline
\end{tabular}

By operating logarithm to the forecasting results "In $y$," the next 15-day maximum load can be obtained, which is shown in Table 11.

MAE (Mean Absolute Error) is computed as follows:

$$
\mathrm{MAE}=\sum_{t} \frac{\left|\hat{y}_{t}-y_{t}\right|}{T},
$$

where $\hat{y}_{t}$ is the prediction value, $y_{t}$ is the actual value, and $T$ is the sample size.

It can be seen in Table 11 that the MAE of the improved ARIMAX model is the minimum, Sigmoid-Function ANN ranked second small, followed by AR model, and ARMA model is the maximum. It means that the improved ARIMAX model is better than S-ANN, AR, or ARMA model according to the AIC and SBC Criterion in Table 11. The revised ARIMAX model is more effective, by which more accurate load results can be obtained.

It can be seen in Figure 3 that the blue line is the actual daily maximum power load data, while the red line is the forecasting data of improved ARIMAX. The difference between improved ARIMAX model and actual power load data is the minimum among these models. Residual stationarity and white noise test show that the residual is stationary white noise sequence, showing that $\varepsilon_{t}=a_{t}$. There is secondorder delay correlation between $\ln y$ and $\ln x$. The final fitting model is

$$
\begin{gathered}
\ln y_{t}=2.86647+1.41495 \ln x_{t-2}+\varepsilon_{t}, \\
\varepsilon_{t}=a_{t} .
\end{gathered}
$$

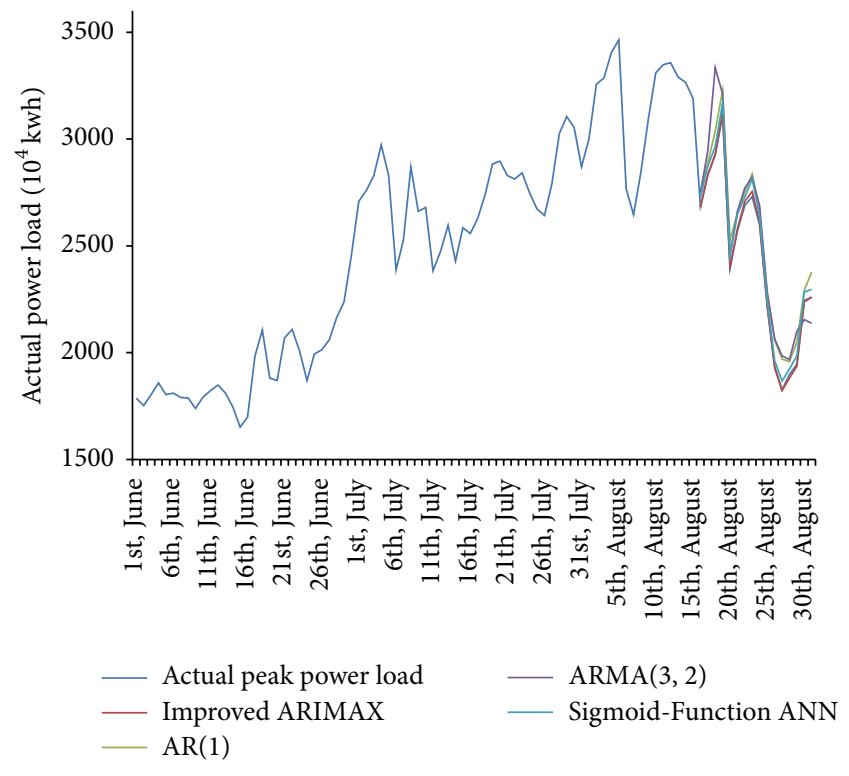

FIgURE 3: Forecasting graphics.

\section{Conclusion}

Based on the above analysis, the improved ARIMAX model can effectively dig up self-related information of load data. As an effective method for short-term load forecasting, the model can get a more accurate prediction result than traditional time series models. Prediction accuracy of this 
TABLE 12: Daily maximum power load and temperature data in some city in 2010.

\begin{tabular}{|c|c|c|c|c|c|}
\hline Time & Peak power load & Maximum temperature & Time & Peak power load & Maximum temperature \\
\hline 1st Jun. & 1787 & 24.9 & 9th Jul. & 2662 & 33.3 \\
\hline 2nd Jun. & 1752 & 23.5 & 10th Jul. & 2679 & 35.6 \\
\hline 3rd Jun. & 1804 & 26.3 & 11th Jul. & 2383 & 32.6 \\
\hline 4th Jun. & 1858 & 28.7 & 12th Jul. & 2473 & 32.2 \\
\hline 5th Jun. & 1804 & 30.2 & 13th Jul. & 2596 & 35.6 \\
\hline 6th Jun. & 1810 & 31.1 & 14th Jul. & 2429 & 31.1 \\
\hline 7th Jun. & 1790 & 25.9 & 15th Jul. & 2585 & 32.8 \\
\hline 8th Jun. & 1788 & 23.8 & 16th Jul. & 2558 & 34.5 \\
\hline 9th Jun. & 1739 & 24.2 & 17th Jul. & 2628 & 35.2 \\
\hline 10th Jun. & 1791 & 25.5 & 18th Jul. & 2739 & 35.1 \\
\hline 11th Jun. & 1822 & 28.2 & 19th Jul. & 2883 & 35.8 \\
\hline 12th Jun. & 1848 & 28.9 & 20th Jul. & 2896 & 36.5 \\
\hline 13th Jun. & 1811 & 22.8 & 21st Jul. & 2829 & 36.8 \\
\hline 14th Jun. & 1746 & 28 & 22nd Jul. & 2812 & 36 \\
\hline 15th Jun. & 1652 & 32.1 & 23rd Jul. & 2841 & 35.6 \\
\hline 16th Jun. & 1698 & 33.2 & 24th Jul. & 2746 & 34.8 \\
\hline 17th Jun. & 1983 & 29.9 & 25th Jul. & 2672 & 32.9 \\
\hline 18th Jun. & 2106 & 33.4 & 26th Jul. & 2642 & 32.6 \\
\hline 19th Jun. & 1881 & 27.7 & 27th Jul. & 2791 & 35.3 \\
\hline 20th Jun. & 1869 & 29.7 & 28th Jul. & 3026 & 36.4 \\
\hline 21st Jun. & 2069 & 32.2 & 29th Jul. & 3105 & 36.8 \\
\hline 22nd Jun. & 2109 & 30.3 & 30th Jul. & 3054 & 37 \\
\hline 23rd Jun. & 2007 & 26.9 & 31st Jul. & 2870 & 36.2 \\
\hline 24th Jun. & 1869 & 27.5 & 1st Aug. & 2999 & 36.7 \\
\hline 25th Jun. & 1994 & 30.3 & 2nd Aug. & 3256 & 38 \\
\hline 26th Jun. & 2014 & 31.4 & 3rd Aug. & 3286 & 38.7 \\
\hline 27th Jun. & 2059 & 32 & 4th Aug. & 3404 & 39.5 \\
\hline 28th Jun. & 2163 & 29.1 & 5th Aug. & 3464 & 40.5 \\
\hline 29th Jun. & 2237 & 32 & 6th Aug. & 2766 & 32.9 \\
\hline 30th Jun. & 2456 & 35.8 & 7th Aug. & 2646 & 33.9 \\
\hline 1st Jul. & 2708 & 35.9 & 8th Aug. & 2847 & 35.7 \\
\hline 2nd Jul. & 2760 & 35.9 & 9th Aug. & 3094 & 36.8 \\
\hline 3rd Jul. & 2829 & 35.6 & 10th Aug. & 3310 & 38.8 \\
\hline 4th Jul. & 2972 & 37 & 11th Aug. & 3348 & 39 \\
\hline 5th Jul. & 2829 & 32.1 & 12th Aug. & 3357 & 37.5 \\
\hline 6th Jul. & 2387 & 28.5 & 13th Aug. & 3290 & 37.8 \\
\hline 7th Jul. & 2528 & 33.7 & 14th Aug. & 3265 & 37.8 \\
\hline
\end{tabular}

model is greatly improved, which is of high value in engineering application area. It is verified by relative error analysis of ARMA and the improved ARIMAX that the revised model has higher prediction accuracy than usual forms.

\section{Notation}

Net $_{k j}$ : The state of network unit $u_{j}$

$o_{k j}: \quad$ Output unit

$\delta_{k j}: \quad$ Output (hidden) layer unit

$\omega_{j i}(0)$ : Initial value of weight or threshold
$X_{k}$ : Training samples

$\varepsilon: \quad$ Accuracy requirements

$\left\{x_{t}\right\}:$ Time series

$E X_{t}:$ Mean of time series $\left\{x_{t}\right\}$

$\phi_{p}: \quad$ Autoregressive coefficient

$\theta_{q}: \quad$ Random interference coefficient

$\Phi(B)$ : Q-order moving average coefficient polynomials

$\Theta(B)$ : Residual sequence moving average coefficient polynomials

$B: \quad$ Delay operator

$\sigma$ : Standard deviation. 


\section{Conflict of Interests}

The authors declare no conflict of interests.

\section{Acknowledgment}

The authors gratefully acknowledge the financial support from the National Natural Science Fund of China (no. 71471061).

\section{References}

[1] S.-M. Chen, "Forecasting enrollments based on fuzzy time series," Fuzzy Sets and Systems, vol. 81, no. 3, pp. 311-319, 1996.

[2] J. L. Torres, A. García, M. De Blas, and A. De Francisco, "Forecast of hourly average wind speed with ARMA models in Navarre (Spain)," Solar Energy, vol. 79, no. 1, pp. 65-77, 2005.

[3] R. G. Kavasseri and K. Seetharaman, "Day-ahead wind speed forecasting using f-ARIMA models," Renewable Energy, vol. 34, no. 5, pp. 1388-1393, 2009.

[4] M. Tamimi and R. Egbert, "Short term electric load forecasting via fuzzy neural collaboration," Electric Power Systems Research, vol. 56, no. 3, pp. 243-248, 2000.

[5] L. Suganthi and A. A. Samuel, "Energy models for demand forecasting-a review," Renewable and Sustainable Energy Reviews, vol. 16, no. 2, pp. 1223-1240, 2012.

[6] K. Huarng and H.-K. Yu, "A dynamic approach to adjusting lengths of intervals in fuzzy time series forecasting," Intelligent Data Analysis, vol. 8, no. 1, pp. 3-27, 2004.

[7] J. Ramón Cancelo, A. Espasa, and R. Grafe, "Forecasting the electricity load from one day to one week ahead for the Spanish system operator," International Journal of Forecasting, vol. 24, no. 4, pp. 588-602, 2008.

[8] H. S. Hipperta, D. W. Bunn, and R. C. Souza, "Large neural networks for electricity load forecasting: are they overfitted?" International Journal of Forecasting, vol. 21, no. 3, pp. 425-434, 2005.

[9] L. Felipe Amarala and R. Castro Souza, "A smooth transition periodic autoregressive (STPAR) model for short-term load forecasting," International Journal of Forecasting, vol. 24, no. 4, pp. 603-615, 2008.

[10] N. Amjady and F. Keynia, "A new neural network approach to short term load forecasting of electrical power systems," Energies, vol. 4, no. 3, pp. 488-503, 2011.

[11] K. Wangdi, P. Singhasivanon, T. Silawan, S. Lawpoolsri, N. J. White, and J. Kaewkungwal, "Development of temporal modelling for forecasting and prediction of malaria infections using time-series and ARIMAX analyses: a case study in endemic districts of Bhutan," Malaria Journal, vol. 9, article 251, 2010.

[12] S. Chadsuthi, C. Modchang, Y. Lenbury, S. Iamsirithaworn, and W. Triampo, "Modeling seasonal leptospirosis transmission and its association with rainfall and temperature in Thailand using time-series and ARIMAX analyses," Asian Pacific Journal of Tropical Medicine, vol. 5, no. 7, pp. 539-546, 2012.

[13] U. Yolcu, E. Egrioglu, V. R. Uslu, M. A. Basaran, and C. H. Aladag, "A new approach for determining the length of intervals for fuzzy time series," Applied Soft Computing Journal, vol. 9, no. 2, pp. 647-651, 2009.

[14] K. Kandananond, "Forecasting electricity demand in Thailand with an artificial neural network approach," Energies, vol. 4, no. 8, pp. 1246-1257, 2011.
[15] C.-C. Hsu and C.-Y. Chen, "Regional load forecasting in Taiwan-applications of artificial neural networks," Energy Conversion \& Management, vol. 44, no. 12, pp. 1941-1949, 2003.

[16] J. Yoo and K. Hur, "Load forecast model switching scheme for improved robustnessto changes in building energy consumption patterns," Energies, vol. 6, no. 3, pp. 1329-1343, 2013.

[17] R. F. Engle and C. W. J. Granger, "Co-integration and error correction: representation, estimation, and testing," in Essays in Econometrics, pp. 145-172, Harvard University Press, Cambridge, Mass, USA, 2001, http://dl.acm.org/citation.cfm?id= 781849 .

[18] H. Zhang, Z. Wang, and D. Liu, "Global asymptotic stability of recurrent neural networks with multiple time-varying delays," IEEE Transactions on Neural Networks, vol. 19, no. 5, pp. 855873, 2008.

[19] X.-G. Liu, R. R. Martin, M. Wu, and M.-L. Tang, "Global exponential stability of bidirectional associative memory neural networks with time delays," IEEE Transactions on Neural Networks, vol. 19, no. 3, pp. 397-407, 2008.

[20] A. Azadeh, S. F. Ghaderi, and S. Sohrabkhani, "A simulatedbased neural network algorithm for forecasting electrical energy consumption in Iran," Energy Policy, vol. 36, no. 7, pp. 2637-2644, 2008.

[21] M. Espinoza, J. A. Suykens, and B. de Moor, "Fixed-size least squares support vector machines: a large scale application in electrical load forecasting," Computational Management Science, vol. 3, no. 2, pp. 113-129, 2006.

[22] M. G. Karlaftis and E. Vlahogianni, "Statistical methods versus neural networks in transportation research: differences, similarities and some insights," Transportation Research Part C: Emerging Technologies, vol. 19, no. 3, pp. 387-399, 2011.

[23] H. Niska, T. Hiltunen, A. Karppinen, J. Ruuskanen, and M. Kolehmainen, "Evolving the neural network model for forecasting air pollution time series," Engineering Applications of Artificial Intelligence, vol. 17, no. 2, pp. 159-167, 2004.

[24] Z. Ma, J. Xing, M. Mesbah, and L. Ferreira, "Predicting shortterm bus passenger demand using a pattern hybrid approach," Transportation Research Part C: Emerging Technologies, vol. 39, pp. 148-163, 2014.

[25] W. Wang, J. Jin, and Y. Li, "Prediction of inflow at three Gorges dam in Yangtze River with wavelet network model," Water Resources Management, vol. 23, no. 13, pp. 2791-2803, 2009.

[26] K. Afshar and N. Bigdeli, "Data analysis and short term load forecasting in Iran electricity market using singular spectral analysis (SSA)," Energy, vol. 36, no. 5, pp. 2620-2627, 2011.

[27] B. Premanode and C. Toumazou, "Improving prediction of exchange rates using differential EMD," Expert Systems with Applications, vol. 40, no. 1, pp. 377-384, 2013.

[28] X. H. Yang, D. X. She, Z. F. Yang, Q. H. Tang, and J. Q. Li, "Chaotic bayesian method based on multiple criteria decision making (MCDM) for forecasting nonlinear hydrological time series," International Journal of Nonlinear Sciences \& Numerical Simulation, vol. 10, no. 11-12, pp. 1595-1610, 2009.

[29] S. Razavi and B. A. Tolson, "A new formulation for feedforward neural networks," IEEE Transactions on Neural Networks, vol. 22, no. 10, pp. 1588-1598, 2011.

[30] A. Alvarez, A. Orfila, and J. Tintore, "DARWIN: an evolutionary program for nonlinear modeling of chaotic time series," Computer Physics Communications, vol. 136, no. 3, pp. 334-349, 2001.

[31] H. Kantz and T. Schreiber, Nonlinear Time Series Analysis, Cambridge University Press, Cambridge, UK, 1997. 
[32] M. Ardalani-Farsa and S. Zolfaghari, "Residual analysis and combination of embedding theorem and artificial intelligence in chaotic time series forecasting," Applied Artificial Intelligence, vol. 25, no. 1, pp. 45-73, 2011.

[33] Y.-H. Chen and F.-J. Chang, "Evolutionary artificial neural networks for hydrological systems forecasting," Journal of Hydrology, vol. 367, no. 1-2, pp. 125-137, 2009.

[34] K. A. de Oliveira, A. Vannucci, and E. C. da Silva, "Using artificial neural networks to forecast chaotic time series," Physica A: Statistical Mechanics and Its Applications, vol. 284, no. 1, pp. 393-404, 2000.

[35] G. G. Szpiro, "Forecasting chaotic time series with genetic algorithms," Physical Review E-Statistical Physics, Plasmas, Fluids, and Related Interdisciplinary Topics, vol. 55, no. 3, pp. 2557-2568, 1997. 


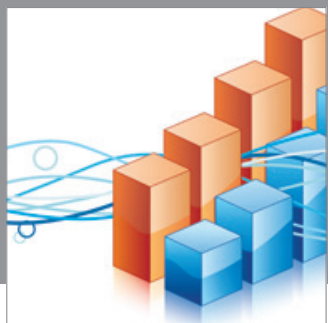

Advances in

Operations Research

mansans

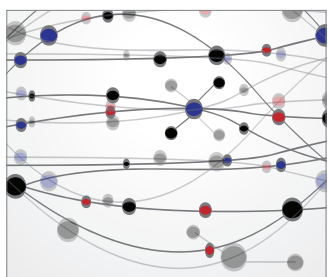

The Scientific World Journal
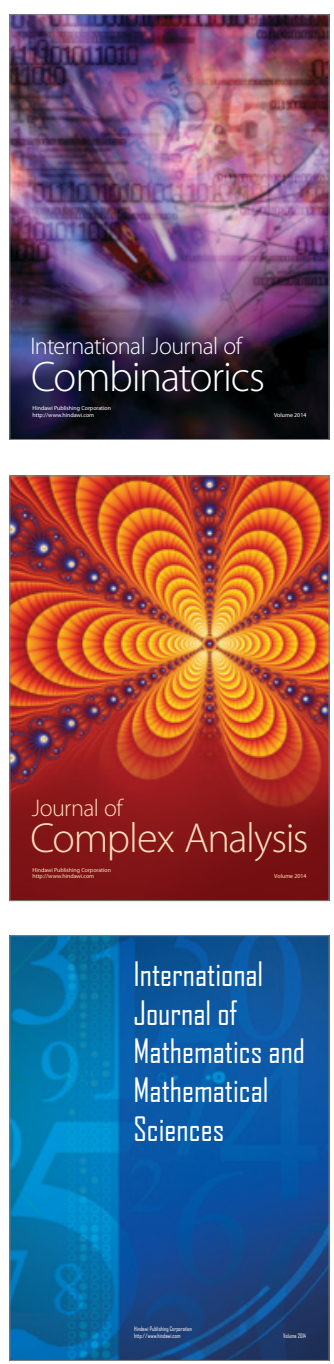
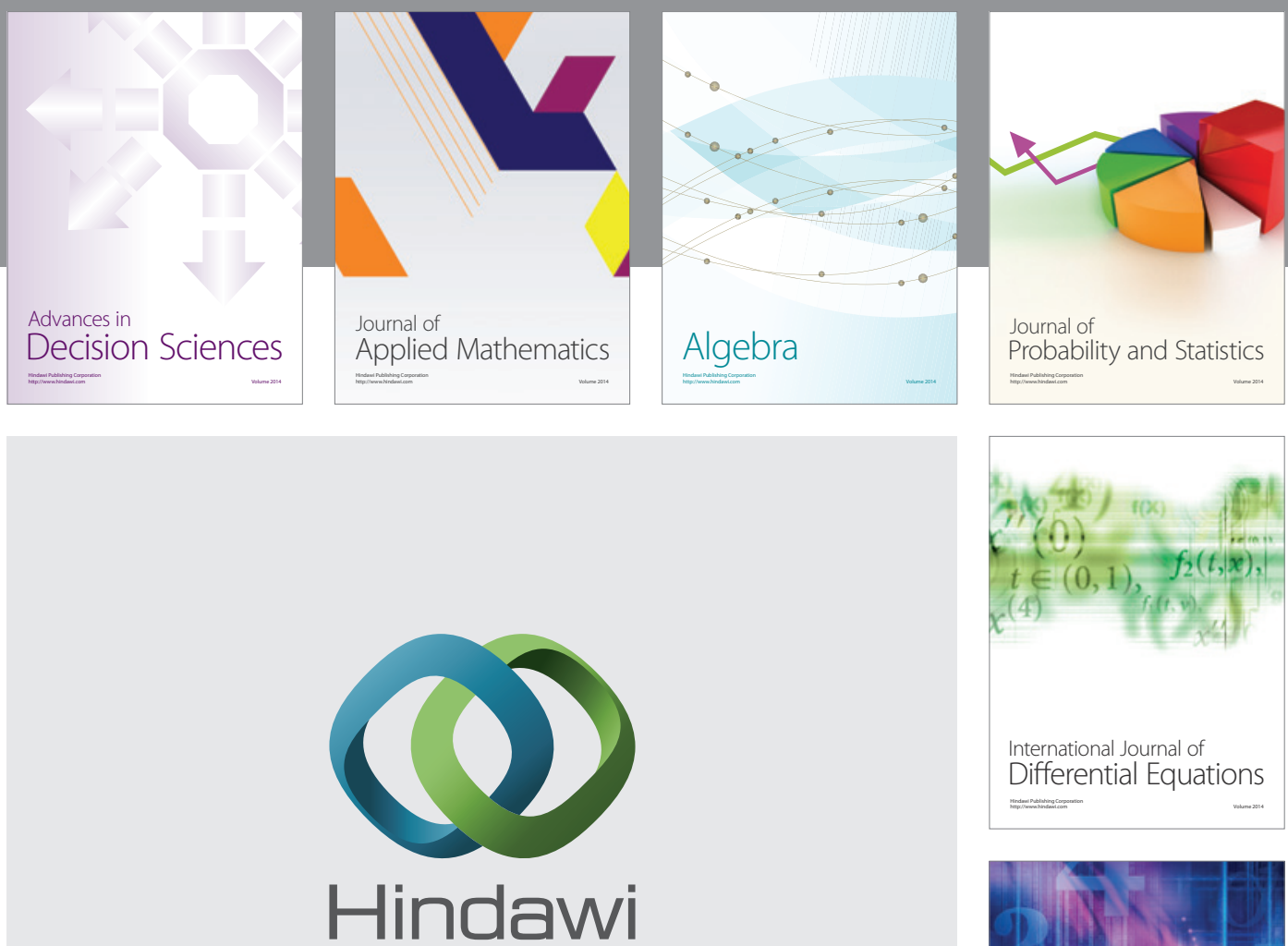

Submit your manuscripts at http://www.hindawi.com
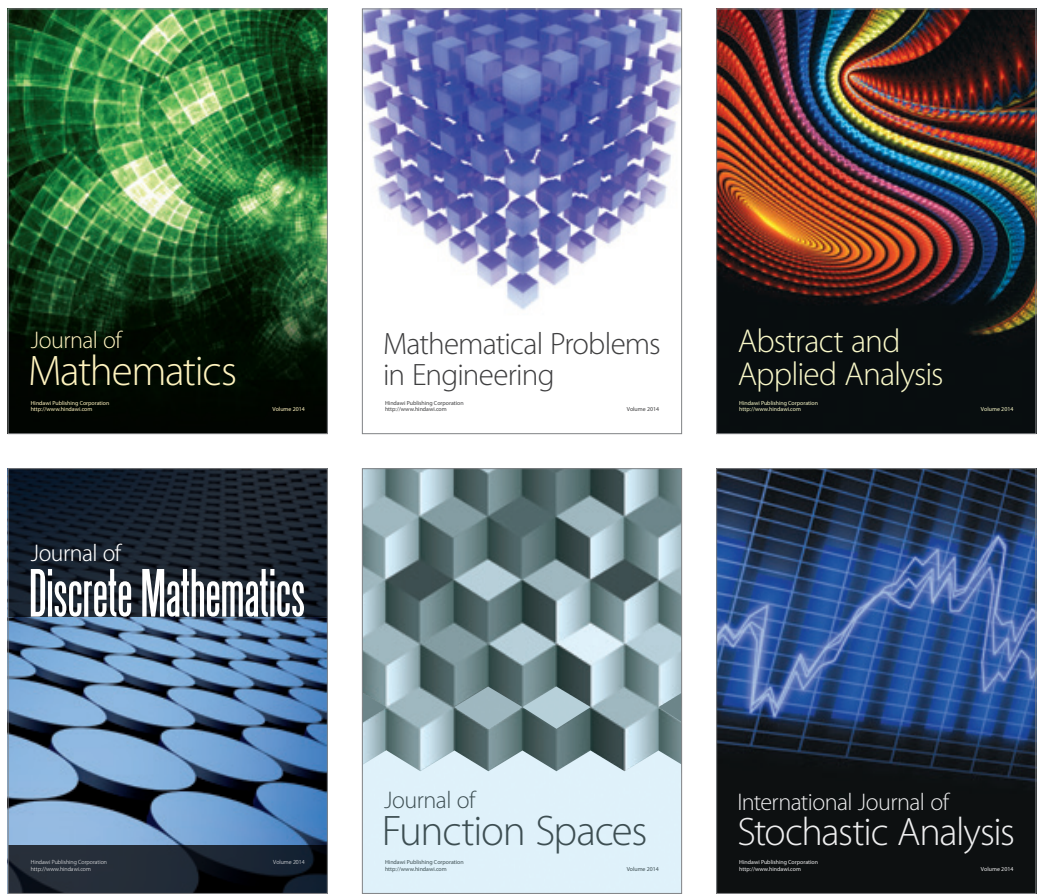

Journal of

Function Spaces

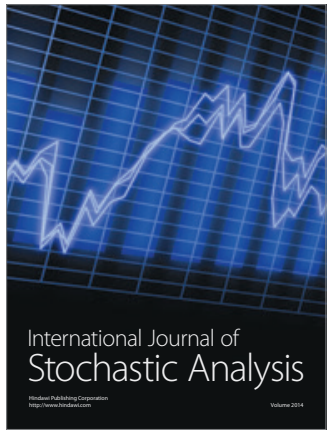

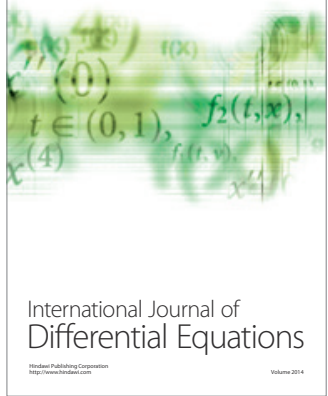
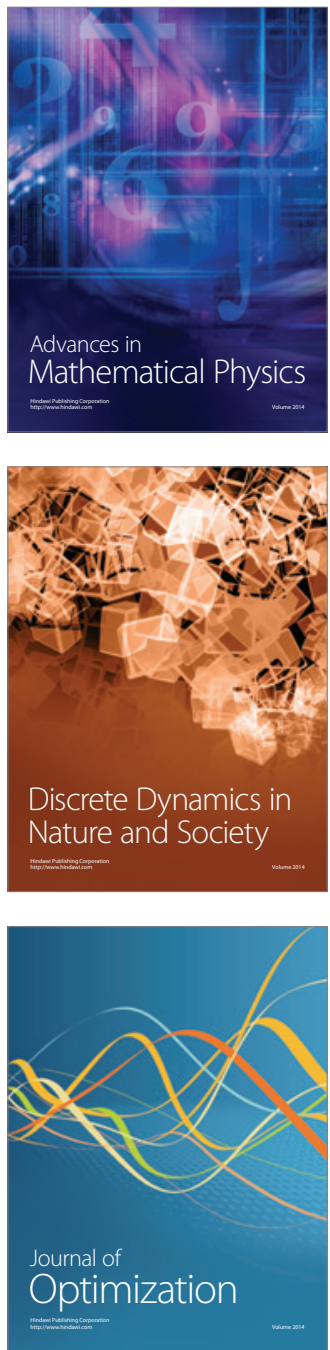